(2) Open Access Full Text Article

REVIEW

\title{
Levodopa-induced dyskinesias in Parkinson's disease: emerging treatments
}

\author{
This article was published in the following Dove Press journal: \\ Neuropsychiatric Disease and Treatment \\ 21 October 2013 \\ Number of times this article has been viewed
}

\section{Panagiotis Bargiotas Spyridon Konitsiotis}

Department of Neurology, University of loannina, loannina, Greece
Correspondence: Spyridon Konitsiotis Department of Neurology, Medical School, University of loannina, PO Box I I 86, loannina 45 I I0, Greece Tel +30 2651007514 Fax +302651099630 Email skonitso@uoi.gr

\begin{abstract}
Parkinson's disease therapy is still focused on the use of L-3,4-dihydroxyphenylalanine (levodopa or L-dopa) for the symptomatic treatment of the main clinical features of the disease, despite intensive pharmacological research in the last few decades. However, regardless of its effectiveness, the long-term use of levodopa causes, in combination with disease progression, the development of motor complications termed levodopa-induced dyskinesias (LIDs). LIDs are the result of profound modifications in the functional organization of the basal ganglia circuitry, possibly related to the chronic and pulsatile stimulation of striatal dopaminergic receptors by levodopa. Hence, for decades the key feature of a potentially effective agent against LIDs has been its ability to ensure more continuous dopaminergic stimulation in the brain. The growing knowledge regarding the pathophysiology of LIDs and the increasing evidence on involvement of nondopaminergic systems raises the possibility of more promising therapeutic approaches in the future. In the current review, we focus on novel therapies for LIDs in Parkinson's disease, based mainly on agents that interfere with glutamatergic, serotonergic, adenosine, adrenergic, and cholinergic neurotransmission that are currently in testing or clinical development.
\end{abstract}

Keywords: motor fluctuations, dopaminergic/nondopaminergic systems, pharmacotherapy

\section{Introduction}

Parkinson's disease (PD) is a common neurodegenerative disorder with a wide spectrum of clinical features, including motor symptoms, gait and balance disorders, and cognitive, emotional, and behavioral deficits. The cardinal signs of PD reflect a decline in striatal dopamine (DA) due to the degeneration of neurons arising from the pars compacta of the substantia nigra. The application of levodopa restores DAergic transmission deficiency and provides remarkable symptomatic relief to the vast majority of patients with PD, and remains the most efficacious agent available for PD treatment. However, soon after the first clinical introduction of levodopa as an antiparkinsonian agent by George Cotzias, ${ }^{1}$ it became apparent that the beneficial effect of levodopa is not permanent, and that its long-term use could cause a behavioral and molecular sensitization such that each exposure to a direct or indirect stimulant of DAergic transmission influences the response to a subsequent stimulus, a procedure known as priming. This narrows the therapeutic window of levodopa, and a variety of motor problems that are extremely disabling for the patient, known as motor-response complications, can occur. One of the most discomforting and frequent features of motor-response complications is the emergence of abnormal and involuntary movements affecting mainly the facial muscles, but also the neck, upper and lower limbs, and body axis, termed levodopa-induced dyskinesia (LID). 
Chorea and dystonia are the most frequent forms of LIDs, but ballismus and myoclonus can appear as well. The occurrence of LIDs is directly related to the plasma concentration of levodopa. Three main forms of LIDs have been characterized: 1) "peak-dose" dyskinesias are choreic movements related to high levodopa plasma concentrations; 2) diphasic on/off dyskinesias, which coincide with rising and decreasing plasma concentrations of levodopa and might include both chorea and dystonia; and 3) "off" dystonia, which is an often-painful dystonic posture, appears early in the morning or at night, and characterizes the unmedicated state where plasma levels of levodopa are very low.

Approximately $50 \%$ of patients with PD will experience LID roughly 4-5 years after initiation of levodopa treatment. ${ }^{2,3}$ However, the percentage of PD patients experiencing troublesome LIDs (the ones interfering with normal activities) and requiring some intervention is actually much lower than $50 \%$. The presence of LID significantly worsens the quality of life of the patients. ${ }^{4}$ Moreover, in order to improve LID or to prevent its occurrence, the dose of levodopa is reduced and additional, less effective medication is added to the therapy. This significantly affects the effective control of parkinsonian symptoms and increases health care costs. ${ }^{5}$

\section{The pathophysiology of LID}

The pathophysiology of LID is still not fully understood. Dyskinetic animals appear to have profound alterations at the pre- and postsynaptic level of the neural network of basal ganglia. Although current notions attribute these alterations to several factors, such as aging-related neurodegeneration, neuronal plasticity of DAergic and non-DAergic systems, and glutamatergic overabundance, it seems that the progressive neuronal loss in substantia nigra and the pulsatile chronic DAergic stimulation from levodopa are the key players not only for the appearance but for the severity of LID as well.

The stimulation of DA receptors in a noncanonical, noncontinuous way due to the short half-life of levodopa is thought to induce secondary modifications in striatal medium spiny neurons. ${ }^{6}$ These modifications include changes in the intracellular signal-transduction pathways, in the expression of genes, and in the synaptic efficacy of DA and other neurotransmitter receptors. The affected corticostriatal transmission and plasticity sensitize the striatum in a way that expression of LIDs is facilitated. Indeed, dyskinetic rats showed a loss of synaptic depotentiation in response to low-frequency synaptic stimulation in comparison to nondyskinetic rats. ${ }^{7}$
Despite existing data suggesting the opposite, ${ }^{8,9}$ a growing body of evidence indicates that progressive DAergic degeneration in substantia nigra lowers the threshold required for LID to occur, thus amplifying the dyskinesiogenic effect of levodopa. Animals with nigrostriatal lesions were at a significantly higher risk of developing LIDs after levodopa administration when compared to less lesioned controls. ${ }^{10} \mathrm{In}$ addition, the percentage of DAergic loss in substantia nigra is positively correlated with the severity of levodopa-induced involuntary movements in a rat model. ${ }^{11}$ These findings were indirectly confirmed by the finding that in dopamineresponsive dystonia, where in contrast to PD the nigrostriatal terminals are preserved, the chronic administration of levodopa is not related to the development of LID. ${ }^{12}$ One model that could explain the close relation between nigrostriatal denervation and LID is based on the dysregulation of release and reuptake of DA from the synaptic cleft. In the normal brain as well as in the early phase of PD, where only minor nigrostriatal degeneration is observed, exogenously administered levodopa is incorporated in DAergic neurons, converted to DA, and released via vesicles in the synaptic cleft. The action of DA at the synapse is terminated by its clearance across the presynaptic membrane with the action of the DA-reuptake transporter. With disease progression and further DAergic cell loss, this machinery of DA conversion and regulation is severely compromised, and the availability of DA depends highly on the pharmacokinetic characteristics and the bioavailability of exogenous levodopa, which explains the occurrence of LIDs in relation to levodopa dosage. Moreover, other cells, such as serotonergic neurons, try to compensate for the DAergic loss by converting exogenous levodopa to DA. However, these cells are not equipped with the proper regulatory machinery at the presynaptic level, which results in a defective release and reuptake of synaptic DA, thus leading to an abnormal and irregular postsynaptic stimulation of the striatal DA receptors..$^{13-16}$

\section{Emerging treatments for LID}

Treating LID or preventing its appearance is an open challenge in the field of PD treatment. In the last few decades, the consensus that providing continuous DAergic stimulation would modulate the expression of LIDs led to the development of several therapeutic approaches that unfortunately were found to be only partially effective. These approaches were based on the use of DA agonists that reduced the risk of motor complications, but were proved to be less effective regarding the control of parkinsonian symptoms in comparison to levodopa, and most importantly were associated with 
serious adverse effects. The $N$-methyl-d-aspartate (NMDA) antagonist amantadine, despite being far from a perfect drug, is the only widely used antidyskinetic agent in everyday clinical practice (see details later in this paper). On the other hand, the introduction of Duodopa and deep-brain stimulation made possible the reduction of daily levodopa dosage and proved to be very beneficial, especially for patients with severe disabling LIDs. ${ }^{17,18}$ However, both interventions are invasive, restricted to specific selection criteria and certainly not side effect-free.

In recent years, great effort has been made to characterize non-DAergic mechanisms that contribute to LID expression. These include changes in glutamatergic, serotonergic, adenosine, adrenergic, and cholinergic neurotransmission. The pharmacological targeting of compounds related to those systems could reduce or prevent and delay the development of LIDs. Therefore, preclinical and clinical research is currently focused on developing and testing novel agents that influence both DAergic and non-DAergic transmission (for clinical trials see Table 1).

\section{Glutamate-receptor antagonists}

There are ample data suggesting an active involvement of glutamate receptors (GluRs) in the acute expression and development of LID. Although several mechanisms have been suggested, it seems that changes in thalamo- and corticostriatal glutamatergic transmission are of significant importance. The striatum receives massive cortical and thalamic glutamatergic inputs. In PD patients with LID, an increase in NMDA-, metabotropic Glu (mGlu)-, and $\alpha$-amino-3-hydroxy-5-methyl-4-isoxazolepropionic acid (AMPA)-receptor binding have been reported. ${ }^{19}$ This might explain the loss of spines in medium spiny neurons, since DAergic neurons in the substantia nigra appear to be hypersensitive to glutamatergic action. ${ }^{20}$ The Glu-mediated neuronal degeneration in turn facilitates the expression of LIDs after levodopa treatment, as mentioned earlier.

\section{NMDA antagonists}

Significant changes in the synaptic abundance of NMDA receptors have been found in the striata of dyskinetic animals. ${ }^{21}$ Moreover, abnormal phosphorylation and synaptic redistribution of several NMDA-subunit receptors seem to play an important role in the expression of dyskinesias, and have been reported in the dyskinetic state. ${ }^{22-24}$ Despite existing data at the preclinical level showing the antidyskinetic effect of several NMDA modulators, the results from clinical trials using NMDA antagonists for the treatment of LID have been so far not that exciting. This is mainly due to the limited therapeutic effect and the potentially serious adverse effects associated with a nonselective blockade. Therefore, no agent of this group, including amantadine, has been approved for the treatment of dyskinesia.

Amantadine, a low-affinity, noncompetitive NMDAreceptor antagonist, proved to be effective in reducing LIDs in preclinical and clinical settings, providing strong evidence for the involvement of the glutamatergic system in the pathophysiology of LIDs. Early animal studies showed that amantadine improved LIDs without significant loss of the levodopa-induced antiparkinsonian benefit. ${ }^{25,26}$ Later, a significant number of clinical trials confirmed these results in patients with PD. ${ }^{27-30}$ However, other studies raised questions about the duration of the antidyskinetic effect of amantadine, and the results were controversial. Thomas et al reported loss of effect after 9 months, ${ }^{31}$ whereas other studies reported long-term benefits from amantadine. ${ }^{27,32}$ Recently, it has been shown that treatment with amantadine prior to the use of levodopa neither delayed onset of LID nor reduced the incidence of LID. ${ }^{33}$

Currently, there is an ongoing multicenter, randomized, double-blind, placebo-controlled study to evaluate the tolerability and efficacy of each of three dose levels of ADS-5102 oral capsules, an extended-release formulation of amantadine, dosed once daily for the treatment of LID in subjects with PD. The use of ADS-5102 is expected to improve safety and tolerability of amantadine via the stabilization of its plasma concentrations during the day and overnight (NCT01397422). ${ }^{34}$

Other agents that block NMDA receptors have also been tested in PD patients with motor fluctuations. In randomized clinical studies, remacemide, an uncompetitive NMDAreceptor antagonist, and riluzole, an antiglutamatergic compound that can also inhibit NMDA receptors noncompetitively, showed no antidyskinetic effect, ${ }^{35,36}$ whereas dextromethorphan reduced dyskinesia by only $30 \%-40 \%$ without affecting the beneficial effect of levodopa. ${ }^{37}$ Dextromethorphan is rapidly and extensively metabolized by hepatic cytochrome P450 (CYP)-2D6. Therefore, without blocking CYP2D6, plasma dextromethorphan levels in some recipients have been undetectably low. ${ }^{38} \mathrm{~A}$ clinical trial to evaluate the efficacy, safety, and tolerability of AVP-923 capsules containing $45 \mathrm{mg}$ dextromethorphan and $10 \mathrm{mg}$ quinidine (a potent CYP2D6 inhibitor) compared to placebo for the treatment of LID in patients with PD is currently recruiting participants (NCT01767129). ${ }^{39}$

Memantine is also a potent nonselective NMDA inhibitor, and its efficacy against LIDs has been tested in an early 
study, with no improvement reported. ${ }^{40}$ However, a recent small double-blind, placebo-controlled pilot study in PD patients with axial symptoms and motor fluctuations showed that memantine slightly reduced LIDs. ${ }^{41}$ Accordingly, the introduction of memantine to daily medication significantly improved LID in several patients with motor complications, whereas other antidyskinetic drugs failed to do so. ${ }^{42,43}$ Given the good tolerability and safety of memantine and the aforementioned positive reports, a clinical trial designed to evaluate the efficacy of memantine further for the treatment of LIDs would have been of significant value.

During the last few years, a number of studies have tested selective NMDA antagonists in the treatment of LIDs, though without impressive results so far. The NMDA-subunit NR2Bspecific inhibitor CP-101,606 prevented the expression of levodopa-induced motor complication in a rat model of $\mathrm{PD}^{44}$; however, another study using a different animal model failed to report its beneficial antidyskinetic effect. ${ }^{45} \mathrm{CP}-101,606$ has been tested in a randomized, double-blind, placebocontrolled clinical trial and failed to improve parkinsonism, showing only mild antidyskinetic action. Moreover, tolerability issues have been raised, since dose-related side effects, such as amnesia and dissociation, have been reported. ${ }^{46}$

Neu-120 is a highly potent and selective uncompetitive NMDA-receptor modulator aiming at reducing LID. It also inhibits monoamine oxidase $\mathrm{B}$ (MAO-B) and glycogen synthase kinase-3 $\beta$ activities in vitro, but does not interact with other receptors, transporters, or enzymes. Neu-120 has been tested in several experimental models of PD and a completed Phase I study (unpublished data, http:// www.neurim.com/products), and currently a clinical trial is evaluating its efficacy in reducing LID in patients with advanced-phase idiopathic PD and motor-response complication (NCT00607451). ${ }^{47}$

\section{Metabotropic glutamate-receptor antagonists}

mGlu receptors (mGluRs) are found abundantly in the basal ganglia, and they regulate neuronal excitability and synaptic functions. A significant number of preclinical studies have highlighted the involvement of mGluRs in the pathophysiology of LIDs. Pharmacological and neuroimaging studies failed to report an involvement of $\mathrm{mGlu} 2 / 3$ receptors in LID, ${ }^{48,49}$ and thus the mGluR5 subtype seems to play a key role in the treatment of LIDs.

mGlu5Rs interact strongly with NMDA receptors and amplify their currents. Antagonists of mGluR5 reduce overactivity of NMDA receptors and resulting overexcitability, both important factors in the expression of LIDs.
Interestingly, several studies suggested a neuroprotective role of the mGluR5 blockade, possibly by delaying neuronal degeneration. ${ }^{50,51}$ The results from preclinical studies testing mGluR5 inhibitors against LIDs are exciting. ${ }^{52-55}$ Perhaps the first study to report that mGluR5 antagonists may prove useful for the symptomatic treatment of LID was Dekundy et al. In this study, MTEP (((2-methyl-1,3-thiazol-4-yl)ethynyl) pyridine) alleviated LID (at 2.5 and $5 \mathrm{mg} / \mathrm{kg}$ ) in 6-hydroxyDA-lesioned rats. ${ }^{56}$

mGluR5 antagonists have been recently tested in humans as well. AFQ056, a novel mGluR5 antagonist, reduced LIDs in an animal model without affecting the antiparkinsonian effect of levodopa. ${ }^{57}$ In the clinical setting, two studies by Berg et al demonstrated that AFQ056 successfully alleviated established LIDs without worsening other parkinsonian features. Patients with moderate-to-severe LID (study 1) and severe LID (study 2) on stable DAergic therapy received 25-150 mg AFQ056 or placebo twice daily for 16 days. Using dyskinesia and involuntary-movement scales, both studies showed that AFQ056-treated patients exhibited a statistically significant clinical improvement in comparison to placebotreated patients. Mild side effects, such as fatigue, psychiatric and gastrointestinal disorders, and most commonly dizziness, have been reported in both studies. Worsening of dyskinesia associated with stopping treatment was the most common serious adverse effect in both studies. ${ }^{58}$ Another recent clinical trial tested AFQ056 in several doses versus placebo, and demonstrated that with $200 \mathrm{mg}$ daily a significant antidyskinetic effect without worsening of motor symptoms. However, similar to previous studies, AFQ056 was associated with increased adverse effects, with dizziness, fatigue, hallucination, and dyskinesia being the most common. ${ }^{59}$ A clinical trial to assess the long-term safety, tolerability, and efficacy of AFQ056 is ongoing (NCT01173731). ${ }^{60}$

A randomized, double-blind, placebo-controlled clinical study on safety and tolerability of dipraglurant (AX48621), a negative allosteric modulator of mGluR5, was recently published. The secondary objectives of the study included the evaluation of the compound's efficacy in reducing LID compared with placebo in patients with PD. Dipraglurant showed no adverse effect on levodopa efficacy, increased daily "on" time without dyskinesia, reduced daily "off" time, and improved dyskinesia. No safety or tolerability issues have been raised (NCT01336088). ${ }^{61}$

\section{AMPA-receptor antagonists}

The promising antidyskinetic results from NMDA-receptor antagonism prompted many researchers to investigate other 
receptors of the glutamatergic system, such as the AMPA receptors, as potential contributors in the expression of LID. More evidence regarding the involvement of AMPA receptors came from early studies in primates, where talampanel, an AMPA-receptor antagonist, enhanced the antiparkinsonian effect and improved LIDs. ${ }^{62}$ Several clinical studies (NCT00108667, ${ }^{63}$ NCT00036296, ${ }^{64}$ NCT00004576 65 ) evaluated the effect of talampanel in PD and LID, but so far no data have been published.

Recently, three clinical studies testing perampanel, a selective non-competitive AMPA-type Glu-receptor antagonist, have been published. All of them reported no significant changes in PD symptoms and dyskinesia in any perampanel group versus placebo. ${ }^{66-68}$ To the best of our knowledge, no further clinical trials testing AMPA-receptor antagonists have been announced.

\section{$\alpha 2$-Adrenergic-receptor antagonists}

A significant number of studies have suggested an important role for $\alpha$ - and $\beta$-adrenergic receptors in the expression of the dyskinetic phenotype. Most of the studies have been focused on the $\alpha 2$-adrenergic-receptor antagonists idazoxan and fipamezole, and both have been found to be effective in reducing LID when administered in animals. ${ }^{69-71}$

The data in the clinical setting, though, are somehow controversial. Idazoxan showed antidyskinetic properties in patients with $\mathrm{LID},{ }^{72}$ but the same dosage in another trial proved to be ineffective and caused adverse effects. ${ }^{73}$ Fipamezole was tested in a double-blind, randomized, placebo-controlled, dose-escalating 28-day study in patients with LID from the US and India, and was found to be effective only in the US subpopulation. ${ }^{74}$ Two other studies to evaluate mainly safety and tolerability issues, as well as the maximum tolerated dosage in patients with PD who are receiving levodopa, have been conducted (NCT01140841, ${ }^{75}$ NCT0114981176). To our knowledge, no results have been published so far.

\section{Adenosine $A_{2 A}$-receptor antagonist}

Presynaptic $\mathrm{A}_{2 \mathrm{~A}}$ adenosine receptors are abundantly expressed in basal ganglia, and can modulate $\gamma$-aminobutyric acid (GABA)-ergic synaptic transmission by increasing the excitability of medium spiny neurons in the striatum and by enhancing GABA inhibition in globus pallidus projection neurons. On the other hand, DA in the intact caudate-putamen dampens this activity. Hence, in the DAdepleted caudate-putamen in $\mathrm{PD}, \mathrm{A}_{2 \mathrm{~A}}$-receptor antagonists could modulate striatopallidal output balance and alleviate parkinsonian symptoms by preventing the excessive activity of striatopallidal neurons. ${ }^{77,78}$

Additionally, $\mathrm{A}_{2 \mathrm{~A}}$ adenosine receptors participate in the planning and execution of movements, probably by influencing $\mathrm{D}_{2}$ - and $\mathrm{D}_{1}$-receptor activity. ${ }^{79}$ Similarly to Glu, adenosine-receptor activity is increased in the parkinsonian state, and this might inhibit motor activity. ${ }^{80}$ The $\mathrm{A}_{2 \mathrm{~A}}$ adenosine-receptor antagonists modulate (probably via regulation of specific neuropeptides, such as dynorphin and enkephalin) the effects of chronic levodopa administration in synaptic plasticity and contribute possibly to the expression of LID. ${ }^{81}$

This profound implication, despite the relative lack of solid data on the effectiveness of $\mathrm{A}_{2 \mathrm{~A}}$ adenosine receptor antagonists against LID in the preclinical setting, led several researchers to test adenosine $\mathrm{A}_{2 \mathrm{~A}}$-receptor antagonists in patients with $\mathrm{PD}$. Preladenant (Sch 420814), a potent and selective competitive antagonist of the $\mathrm{A}_{2 \mathrm{~A}}$ adenosine receptor, showed promising results in mouse models of movement disorders, ${ }^{82,83}$ but failed to influence LID positively in a Phase II, double-blind, randomized trial where "on" time troublesome or nontroublesome dyskinesia was included as a secondary outcome. ${ }^{84}$ However, a significant increase in "off" time has been reported. A subsequent long-term, multicenter, open-label safety and tolerability extension of that study in subjects with fluctuating PD has been recently published. The improvement in "on" and "off" times was sustained, but no antidyskinetic effects have been reported; on the contrary, the preladenant group showed increased dyskinesia rates. ${ }^{85}$

Istradefylline, another adenosine $\mathrm{A}_{2 \mathrm{~A}}$ antagonist, proved to be mildly effective in relieving wearing-off fluctuations in PD patients. However, similarly to preladenant, regarding the troublesome and nontroublesome dyskinesia, the addition of the drug was associated with a slight increase in "on" time with dyskinesia, and dyskinesia was reported as an adverse event more commonly in istradefylline- than in placebo-treated groups. ${ }^{86-89}$ In the most recent study, in 610 patients with PD and motor fluctuations, the primary outcome - reduction in "off" time - was not met, but $40 \mathrm{mg}$ istradefylline per day significantly improved motor score (Unified PD Rating Scale [UPDRS]). However, as previously mentioned, the most commonly reported drug-related adverse effect was dyskinesia (placebo, 2.5\%; $20 \mathrm{mg} /$ day istradefylline, $8.5 \%$; $40 \mathrm{mg}$ /day istradefylline, $6.4 \%){ }^{88}$

Bara-Jimenez et al suggested in an early study that only after lowering the levodopa dose did istradefylline show a clear antidyskinetic effect, ${ }^{90}$ yet more data and clinical trials are needed in order to further test this finding. 
Recently, a double-blind, randomized, placebo-controlled study of the safety and efficacy of tozadenant (SYN115) in PD patients with "wearing-off" fluctuations, including evaluation of dyskinesia as a secondary outcome measure, was published. Patients in tozadenant-treated groups, especially those who received $120 \mathrm{mg}$ and $180 \mathrm{mg}$, reported significant improvement in primary outcomes, without any effect on the expression of troublesome dyskinesias in comparison to placebo. ${ }^{91}$

\section{Nicotinic acetylcholine-receptor agonists}

Nicotinic receptors have been also implicated in the expression of LID in PD. Nicotinic receptors colocalize with DA receptors, ${ }^{92}$ and although the mechanism by which the activation of nicotinic receptors influences the expression of LIDs remains unknown, it is believed that this effect is mediated via regulation of DA release in striatum. ${ }^{93}$

Nicotine, a nonspecific agonist of nicotinic receptors, is very effective in preventing the occurrence of LIDs and reducing established LIDs in several parkinsonian animal models. ${ }^{94-97}$ However, all the preclinical results come from just one laboratory, and thus should be interpreted with caution. The antidyskinetic efficacy of nicotine has been rather disappointing in clinical settings. Nicotine is poorly tolerated, showing side effects related to the autonomic nervous system, possibly due to its nonspecificity towards critical nicotinic receptors. ${ }^{98}$ Interestingly, SIB-1508Y, despite being selective for $\alpha_{4} \beta_{2}$ nicotinic acetylcholinereceptor agonists, showed very low tolerability as well, and the randomized placebo-controlled study testing its efficacy in patients with PD had to be redesigned..$^{99}$

Pharmacological studies with nicotinic-receptor agonists have focused on their potential to improve parkinsonian symptoms, but none of them included the antidyskinetic effect as a primary outcome. Improvement in motor scales have been reported by Villafane et al, ${ }^{100}$ while Vieregge et al, in a randomized double-blind study, suggested that transdermal nicotine as an add-on treatment is not effective for the treatment of PD symptoms. ${ }^{101}$ Recently, a study where nicotine dehydrate bitartrate was given as an oral capsule instead of a transdermal patch was completed, but to date no data have been published (NCT00957918). ${ }^{102}$

At the preclinical level, there is growing evidence that the nicotine-mediated improvement in LIDs involves specific receptors' subunits. ${ }^{103,104}$ Therefore, in the future, drugs that act more selectively at specific subunits of nicotinic receptors could be an attractive approach for the treatment of LIDs.

\section{Partial dopamine agonists}

Partial DA agonists are pharmacological agents able to occupy DA receptors fully (mainly $\mathrm{D}_{2}$ or $\mathrm{D}_{3}$ ) without producing the maximum pharmacological response, as the full agonists do. This might stabilize the DAergic tone in the DA-depleted network, thus preventing the appearance of motor fluctuations and LID, especially when a mild antiparkinsonian effect is required.

Aripiprazole, a partial agonist of $\mathrm{D}_{2} \mathrm{DA}$ and 5-hydroxytryptamine ${ }_{1 \mathrm{~A}}\left(5-\mathrm{HT}_{1 \mathrm{~A}}\right)$ receptors with known antipsychotic action, was well tolerated and reduced significantly the intensity and the frequency of LID in PD patients, while other antidyskinetic treatments failed to do so. ${ }^{105}$ Similarly, preclinical data revealed the antidyskinetic profile of another partial DA $\mathrm{D}_{2}$ agonist, pardoprunox. ${ }^{106}$ At the clinical level, pardoprunox was assessed regarding UPDRS motor score ${ }^{107}$ as well as "on" time without troublesome dyskinesias, ${ }^{108}$ and was found to be effective in comparison to placebo. Doses up to $18 \mathrm{mg} /$ day were well tolerated. ${ }^{109}$

Aplindore has also been tested in patients with PD, but no data have been published yet (NCT00623324). ${ }^{110}$

\section{Monoamine oxidase-B inhibitors}

The pharmacological action of MAO-B inhibitors is the blockade of the enzymatic metabolism of DA in the brain, thus increasing DA concentrations. Based on the idea that an adjunct therapy to levodopa could delay the occurrence of LID, several studies have investigated the effect of MAO-B inhibitors in LID. Waters et al showed that in PD patients who were experiencing motor fluctuations under treatment with levodopa, the time in a dyskinesia-free state was significantly increased in the selegiline patients compared with the placebo group. ${ }^{111}$ Similarly, rasagiline increased daily "on" time without troublesome dyskinesia when used as an add-on therapy in patients with PD and motor fluctuations. ${ }^{12}$

Safinamide, a novel MAO-B and Glu-release inhibitor, reduced LID and increased the duration of the antiparkinsonian response of levodopa in parkinsonian animals. ${ }^{113}$ Several other clinical studies have investigated the effect of safinamide in patients with early PD without motor fluctuation. In a recent placebo-controlled, double-blind trial, a large cohort of patients with mid- to late-stage idiopathic PD with "wearing-off" symptoms and LIDs under optimal treatment received safinamide $(50 \mathrm{mg}$ or $100 \mathrm{mg}$ ) or placebo as an addon therapy. In the $50 \mathrm{mg}$ safinamide group, patients showed significant increases in "on" time without worsening of LIDs, whereas in patients who had severe dyskinesia (Dyskinesia 
Table I Clinical trials for the treatment of LIDs in PD

\begin{tabular}{|c|c|c|}
\hline Pharmacological class & $\begin{array}{l}\text { Substance (references of } \\
\text { completed clinical trials) }\end{array}$ & Outcome* \\
\hline \multirow[t]{8}{*}{ NMDA antagonists } & Amantadine ${ }^{27-33}$ & $\begin{array}{l}\text { Effective against LIDs, controversy concerning the duration of } \\
\text { antidyskinetic effect }\end{array}$ \\
\hline & ADS-5102 & NCT0I397422 (ongoing trial) \\
\hline & Remacemide $^{35}$ & No antidyskinetic effects \\
\hline & Dextromethorphan ${ }^{37}$ & Reduced dyskinesia by $30 \%-40 \%$ \\
\hline & AVP-923 & NCT0I767I29 (ongoing trial) \\
\hline & Memantine $e^{40-42}$ & Possibly effective against LIDs, good tolerability and safety \\
\hline & CP- $101,606^{46}$ & Mild antidyskinetic effect, no improvement in parkinsonism, side effects \\
\hline & Neu- 120 & NCT0060745I (status unknown) \\
\hline \multirow[t]{2}{*}{ mGluR antagonists } & AFQ056 68,59 & $\begin{array}{l}\text { Reduced established LIDs, no negative effect on parkinsonism, safety } \\
\text { and tolerability concerns NCTOI I } 7373 \text { I (ongoing trial) }\end{array}$ \\
\hline & Dipraglurant $(A X 48621)^{61}$ & Improved parkinsonism and dyskinesia NCTOI336088 (completed) \\
\hline \multirow[t]{2}{*}{ AMPA antagonists } & Talampanel & $\begin{array}{l}\text { NCT00 I08667, NCT00036296, NCT00004576 (all trials completed, but } \\
\text { no published data available) }\end{array}$ \\
\hline & Perampanel ${ }^{66-68}$ & No antidyskinetic effects \\
\hline \multirow[t]{2}{*}{$\alpha 2$-adrenergic receptor antagonists } & Idazoxan ${ }^{72,73}$ & Controversial results concerning effectiveness and adverse-effects profile \\
\hline & Fipamezole $\mathrm{e}^{74}$ & $\begin{array}{l}\text { Only partially effective NCTOI I 498I I, NCTOI I 4084 I (completed, } \\
\text { no published data available) }\end{array}$ \\
\hline \multirow[t]{3}{*}{ Adenosine $A_{2 A}$ receptor antagonist } & Preladenant (Sch 4208|4) $)^{84,85}$ & Increase in dyskinesia rates, improvement in parkinsonism \\
\hline & Istradefylline $e^{86-90}$ & Improvement in UPDRS, increased dyskinesia rates \\
\hline & Tozadenant (SYNII5) ${ }^{91}$ & No effect in dyskinesia, improvement in parkinsonian symptoms \\
\hline \multirow[t]{2}{*}{ Nicotinic receptors agonists } & Nicotine $e^{98,100,101}$ & Serious adverse effects NCT00957918 (completed, no published data) \\
\hline & SIB-I508Y & Very low tolerability \\
\hline \multirow[t]{3}{*}{ Partial dopamine agonists } & Aripiprazole ${ }^{105}$ & Effective against LIDs, well tolerated \\
\hline & Pardoprunox ${ }^{107,108}$ & Effective against LIDs and improvement in UPDRS motor score \\
\hline & Aplindore & NCT00623324 (completed, no published data available) \\
\hline \multirow[t]{3}{*}{ Monoamine oxidase-B inhibitors } & Selegiline $\left.\right|^{11,|1| 5,116}$ & Controversial results concerning efficacy against LIDs \\
\hline & Rasagiline $^{1 / 2}$ & Partially effective against LIDs \\
\hline & Safinamide ${ }^{1 / 4}$ & Improvement of LIDs \\
\hline \multirow[t]{3}{*}{ 5HT agonists } & Tandospirone $e^{118}$ & No antidyskinetic effects, worsening of parkinsonism \\
\hline & Sarizotane $\left.\right|^{|19,| 2|,| 22}$ & Controversial results concerning efficacy against LIDs, probably not effective \\
\hline & Piclozotan & NCT00623363 (completed, no published data available) \\
\hline \multirow[t]{6}{*}{ Other treatments } & Valproate ${ }^{125}$ & No antidyskinetic effect \\
\hline & Gabapentin ${ }^{126}$ & No antidyskinetic effect \\
\hline & Zonisamide $^{127}$ & Dose-dependent effectiveness against LIDs \\
\hline & Levetiracetam $^{128-130,133}$ & Only mild antidyskinetic effect \\
\hline & Topiramate & NCT00296959 (early termination due to slow recruitment) \\
\hline & ACR325 (odopidine) & NCTOI023282 (completed, but no published data are available) \\
\hline
\end{tabular}

Notes: aStudy redesigned due to tolerability issues; *status verified on August 22, 2013.

Abbreviations: LIDs, levodopa-induced dyskinesias; PD, Parkinson's disease; NMDA, N-methyl-d-aspartate; mGluRs, metabotropic glutamate receptors; AMPA, $\alpha$-amino-3hydroxy-5-methyl-4-isoxazolepropionic acid; 5HT, 5-hydroxytryptamine; UPDRS, Unified Parkinson's Disease Rating Scale.

Rating Scale >4) and received $100 \mathrm{mg}$ safinamide, both motor fluctuations and LIDs were improved. ${ }^{114}$

On the other hand, the addition of an MAO-B inhibitor increases the availability of DA at the nigrostriatal synapse, and this could lead to an increased occurrence of LIDs. Shoulson et al tested individuals with PD, initially treated with deprenyl (selegiline) who in the progress of the disease had required levodopa. Continuing deprenyl was associated with increased incidences of dyskinesia in comparison to individuals who changed to a matching placebo under double-blind conditions. ${ }^{115}$ The meta-analysis performed by Talati et al, which included the Shoulson et al study, confirmed that coadministration of selegiline with levodopa increases the incidence of LID, despite the decreased need for levodopa. ${ }^{116}$

\section{5-HT agonists}

There is growing evidence that implicates the serotonergic system in the pathophysiology of LID; $;^{16,17}$ however, the exact mechanism is still unknown. As mentioned above, it has been suggested that DAergic degeneration causes the raphestriatal serotonergic system to convert exogenous levodopa to DA that is released and acts as a "false neurotransmitter," which in the absence of autoregulatory mechanisms proper 
to DAergic transmission determines the expression of LIDs. However, in the clinical setting tandospirone failed to induce a clear antidyskinetic effect, and in addition it may worsen the antiparkinsonian effect of levodopa. ${ }^{118}$ Similarly, sarizotan, a compound with full 5-HT ${ }_{1 \mathrm{~A}}$-agonist properties and additional high affinity for $\mathrm{D}_{3}$ and $\mathrm{D}_{4}$ receptors, despite initial data showing promising antidyskinetic effects, ${ }^{119}$ failed to improve dyskinesia significantly in two later double-blind, placebo-controlled, multicenter, multinational trials designed to assess its efficacy and safety in PD patients suffering from LIDs. ${ }^{120-122}$

Piclozotan, a 5-HT ${ }_{1 \mathrm{~A}}$-receptor agonist, significantly reduced levodopa-induced forelimb hyperkinesias and improved motor complications in a rat model of advanced PD. A pilot study with primary outcome measure the "on" time without dyskinesia, testing also adverse effects and pharmacokinetic data of the drug, has been recently completed (NCT00623363). ${ }^{123}$ No preliminary data are available so far.

Bezard et al tested the effects of eltoprazine, a mixed $5-\mathrm{HT}_{1 \mathrm{~A} / 1 \mathrm{~B}}$-receptor agonist, in LIDs in two experimental animal models of PD. The compound proved to be very effective in reducing LID, and was found to potentiate synergistically the antidyskinetic action of amantadine. However the administration of eltoprazine was associated with a worsening of the parkinsonian symptoms. ${ }^{124}$ The study was based on previous data showing that a lesion in the serotonergic system or the administration of a $5-\mathrm{HT}_{1 \mathrm{~A}}$ and a $5-\mathrm{HT}_{1 \mathrm{~B}}$ agonist (and especially their coadministration) resulted in a spectacular decrease of LID. These intriguing results found recent confirmation in a clinical trial testing the antidyskinetic action of eltoprazine; however, to date no publication is available. According to the press release of the study, eltoprazine exhibited a statistically significant reduction in LID at the $5 \mathrm{mg}$ dose $(P=0.0007)$ and the $7.5 \mathrm{mg}$ dose $(P=0.0467)$, while no tolerability and safety issues have been raised (http://www.psychogenics.com/pdf/Positive Efficacy Data in Levodopa Induced Dyskinesia.pdf). ${ }^{125}$

\section{Other treatments}

A therapeutic class of agents that has been intensively tested for the efficacy against LIDs despite having a very different pharmacological profile is anticonvulsants. One of the very first studies to test the antidyskinetic effects of anticonvulsants came from Price et al, who tested sodium valproate for the treatment of LIDs in a double-blind crossover trial with matched placebo and found no significant effect. ${ }^{126}$ In the next two decades, several other antiepileptic agents were tested regarding the effectiveness against motor fluctuations in PD. Gabapentin failed to improve LIDs. ${ }^{127}$ Zonisamide significantly improved PD symptoms, but the positive effect on LID was not consistently documented (improvement only in the $50 \mathrm{mg}$ group, but not in the $25 \mathrm{mg}$ and $100 \mathrm{mg}$ groups versus placebo has been reported). ${ }^{128}$ Similarly, levetiracetam, despite existing data suggesting the opposite, ${ }^{129}$ seems to have only mild antidyskinetic effects ${ }^{130,131}$ in a wide range of doses. In an MPTP (1-methyl-4-phenyl1,2,3,6-tetrahydropyridine)-lesioned marmoset model of PD, treatment with topiramate, a Glu antagonist, significantly improved LID without affecting the antiparkinsonian action of levodopa, thus making topiramate a potentially attractive therapeutic approach for LIDs. However, the only clinical crossover trial to assess the antidyskinetic properties of topiramate in patients with PD and LID was terminated due to slow recruitment, and no data have been published to date (NCT00296959). ${ }^{132}$ Dopidines are a new pharmacological class of agents that act primarily on $\mathrm{DA} \mathrm{D}_{2}$ receptors in a dual way (agonist or antagonist), and therefore they are known as DA stabilizers. Pridopidine, the most widely used compound, was found to be effective as a psychomotor stabilizer, and in clinical studies improved motor function in patients with Huntington's disease.

Based on unpublished preclinical data and positive Phase I results (https://newsclient.omxgroup.com/cdsPublic/ viewDisclosure.action? disclosureId=368187\&messageI $\underline{\mathrm{d}=439581}$ ), a clinical study has been initiated, with safety and tolerability being the primary outcome and the effect of ACR325 (odopidine) on established LIDs the secondary outcome of the study. The trial has been completed, but no published data are available (NCT01023282). ${ }^{133}$

\section{Conclusion}

The management of LID has proved to be a challenging issue in the field of PD treatment. The appearance of LID is not only an unfortunate emergence in the course of PD, having serious negative effects on the quality of the patient's life, but also limits the use of levodopa, the most effective agent so far for the symptomatic control of the disease.

Levodopa induces priming actions due to chronic pulsatile DAergic stimulation, and this is the reason that research interest has been focused, in the last few decades, on agents that could provide more continuous DAergic stimulation. However, this strategy appeared to have several limitations, and the control of LID remained an unsolved problem. Recent findings regarding the pathophysiology of LIDs turned scientific interest towards non-DAergic pathways as 
possible targets for modulating the emergence of LIDs. The results from numerous neuroimaging and pharmacological studies in animals plus postmortem findings were in some cases impressive, and a number of compounds have been further tested in humans. Several studies reported positive results, most notably those using mGluR antagonists and partial DA agonists. However, the majority of the pharmacological agents failed to confirm previously reported safety, tolerability, and effectiveness, a typical example being the antagonists of NMDA and AMPA Glu receptors.

Given the effectiveness (though limited) of amantadine against LID, the positive preclinical data, and the undisputed involvement of NMDA receptors in the pathophysiology of levodopa-induced motor complications, NMDA-receptor antagonists entered the clinical setting as a very promising group of agents for the treatment of LIDs. However, the classical agents that block NMDA receptors in a nonspecific way (remacemide and dextromethorphan) proved to be ineffective in improving LIDs. Similarly, the highly promising results from selected AMPA-receptor antagonists were not confirmed in the clinical setting. The reason for this discrepancy is unknown. Given the structural differences and the degree of complexity between human and rodent brains, one might expect differences in effectiveness and the adverse effects. Moreover, the high prevalence of adverse effects might be associated with the abundance of NMDA receptors in other brain areas, which are not directly involved in motor functions in PD. However, a significant number of clinical trials were based on preclinical data on primates, where this obvious explanation would lose much of its strength. The time the animals were killed during the priming phase ("on" or "off" state) and the lack of a behavioral correlate could also explain discrepancies between clinical data and postmortem findings in animal models. ${ }^{134}$

NMDA receptors consist of several receptor subunits. Studies in experimental models demonstrated that the expression and development of LIDs are associated with changes in selected NMDA subunits, mostly NR2A and NR2B, with the ratio between these two in the molecular composition of NMDA receptors playing a crucial role in the occurrence of LIDs (reviewed in Huot et al). ${ }^{135}$ So far, the results from clinical trials using selective NMDA-receptor antagonists, despite positive preclinical data, have been limited and not that exciting. Differences between toxin-induced parkinsonism in animals and idiopathic PD, as well as differences in the doses of the administered agents, could only partially explain this discrepancy. In the future, determining the specific role of each receptor subunit in the establishment of LID could provide additional information concerning its pathophysiology and facilitate the development of an agent with better selectivity and improved safety.

In conclusion, no truly innovative therapies have come to light in recent years, and treatment options against LIDs remain limited. Maybe what is missing are more sophisticated agents capable of acting in a specific way on several pathways involved in the expression of LID, thus causing a synergistic antidyskinetic effect. However, the recent widening of research focus on non-DAergic pathways in itself is an innovative step towards novel therapeutic approaches, which will hopefully soon lead to more fruitful results regarding this disabling effect of levodopa treatment.

\section{Disclosure}

No sources of funding were used to assist in the preparation of this review. The authors have no conflicts of interest that are directly relevant to the content of this review.

\section{References}

1. Cotzias GC. L-Dopa for Parkinsonism. N Engl J Med. 1968; 278(11):630.

2. Ahlskog JE, Muenter MD. Frequency of levodopa-related dyskinesias and motor fluctuations as estimated from the cumulative literature. Mov Disord. 2001;16(3):448-458.

3. Fahn S. The spectrum of levodopa-induced dyskinesias. Ann Neurol. 2000;47(4 Suppl 1):S2-S9; discussion S9-S11.

4. Chapuis S, Ouchchane L, Metz O, Gerbaud L, Durif F. Impact of the motor complications of Parkinson's disease on the quality of life. Mov Disord. 2005;20(2):224-230.

5. Maurel F, Lilliu H, Le Pen C. Social and economic cost of L-dopainduced dyskinesias in patients with Parkinson's disease. Rev Neurol (Paris). 2001;157(5):507-514. French.

6. Calabresi P, Di Filippo M, Ghiglieri V, Tambasco N, Picconi B. Levodopa-induced dyskinesias in patients with Parkinson's disease: filling the bench-to-bedside gap. Lancet Neurol. 2010;9(11):1106-1117.

7. Picconi B, Centonze D, Håkansson K, et al. Loss of bidirectional striatal synaptic plasticity in L-DOPA-induced dyskinesia. Nat Neurosci. 2003;6(5):501-506.

8. Guigoni C, Dovero S, Aubert I, et al. Levodopa-induced dyskinesia in MPTP-treated macaques is not dependent on the extent and pattern of nigrostrial lesioning. Eur J Neurosci. 2005;22(1):283-287.

9. Linazasoro G, Van Blercom N, Bergaretxe A, Iñaki FM, Laborda E, Ruiz Ortega JA. Levodopa-induced dyskinesias in Parkinson disease are independent of the extent of striatal dopaminergic denervation: a pharmacological and SPECT study. Clin Neuropharmacol. 2009;32(6): 326-329.

10. Di Monte DA, McCormack A, Petzinger G, Janson AM, Quik M, Langston WJ. Relationship among nigrostriatal denervation, parkinsonism, and dyskinesias in the MPTP primate model. Mov Disord. 2000;15(3):459-466.

11. Paillé V, Brachet P, Damier P. Role of nigral lesion in the genesis of dyskinesias in a rat model of Parkinson's disease. Neuroreport. 2004; 15(3):561-564.

12. de la Fuente-Fernández R. Drug-induced motor complications in doparesponsive dystonia: implications for the pathogenesis of dyskinesias and motor fluctuations. Clin Neuropharmacol. 1999;22(4):216-219.

13. Cenci MA, Lundblad M. Post- versus presynaptic plasticity in L-dopainduced dyskinesia. J Neurochem. 2006;99(2):381-392. 
14. Carta M, Carlsson T, Kirik D, Björklund A. Dopamine released from 5-HT terminals is the cause of L-dopa-induced dyskinesia in parkinsonian rats. Brain. 2007;130(Pt 7):1819-1833.

15. Blandini F, Armentero MT. New pharmacological avenues for the treatment of L-dopa-induced dyskinesias in Parkinson's disease: targeting glutamate and adenosine receptors. Exp Opin Investig Drugs. 2012;21(2):153-168.

16. Kannari K, Yamato H, Shen H, Tomiyama M, Suda T, Matsunaga M. Activation of 5-HT(1A) but not 5-HT(1B) receptors attenuates an increase in extracellular dopamine derived from exogenously administered L-dopa in the striatum with nigrostriatal denervation. J Neurochem. 2001;76(5):1346-1353.

17. Annic A, Devos D, Seguy D, Dujardin K, Destée A, Defebvre L. Continuous dopaminergic stimulation by Duodopa in advanced Parkinson's disease: efficacy and safety. Rev Neurol (Paris). 2009; 165(8-9):718-727. French.

18. Deuschl G, Schade-Brittinger C, Krack P, et al. A randomized trial of deep-brain stimulation for Parkinson's disease. N Engl J Med. 2006; 355(9):896-908.

19. Smith Y, Raju D, Nanda B, Pare JF, Galvan A, Wichmann T. The thalamostriatal systems: anatomical and functional organization in normal and parkinsonian states. Brain Res Bull. 2009;78(2-3):60-68.

20. Blandini F. An update on the potential role of excitotoxicity in the pathogenesis of Parkinson's disease. Funct Neurol. 2010;25(2): 65-71.

21. Hallett PJ, Dunah AW, Ravenscroft P, et al. Alterations of striatal NMDA receptor subunits associated with the development of dyskinesia in the MPTP-lesioned primate model of Parkinson's disease. Neuropharmacology. 2005;48(4):503-516.

22. Gardoni F, Picconi B, Ghiglieri V, et al. A critical interaction between NR2B and MAGUK in L-dopa induced dyskinesia. J Neurosci. 2006;26(11):2914-2922.

23. Oh JD, Russell DS, Vaughan CL, Chase TN. Enhanced tyrosine phosphorylation of striatal NMDA receptor subunits: effect of dopaminergic denervation and L-dopa administration. Brain Res. 1998;813(1): $150-159$.

24. Napolitano M, Picconi B, Centonze D, Bernardi G, Calabresi P, Gulino A. L-dopa treatment of parkinsonian rats changes the expression of Src, Lyn and PKC kinases. Neurosci Lett. 2006;398(3):211-214.

25. Blanchet PJ, Konitsiotis S, Chase TN. Amantadine reduces levodopainduced dyskinesias in parkinsonian monkeys. Mov Disord. 1998;13(5):798-802.

26. Lundblad M, Usiello A, Carta M, Håkansson K, Fisone G, Cenci MA. Pharmacological validation of a mouse model of 1-dopa-induced dyskinesia. Exp Neurol. 2005;194(1):66-75.

27. Metman LV, Del Dotto P, LePoole K, Konitsiotis S, Fang J, Chase TN. Amantadine for levodopa-induced dyskinesias: a 1-year follow-up study. Arch Neurol. 1999;56(11):1383-1386.

28. Luginger E, Wenning GK, Bösch S, Poewe W. Beneficial effects of amantadine on L-dopa-induced dyskinesias in Parkinson's disease. Mov Disord. 2000;15(5):873-878.

29. Snow BJ, Macdonald L, McAuley D, Wallis W. The effect of amantadine on levodopa-induced dyskinesias in Parkinson's disease: a double-blind, placebo-controlled study. Clin Neuropharmacol. 2000;23(2):82-85.

30. Del Dotto P, Pavese N, Gambaccini G, et al. Intravenous amantadine improves levadopa-induced dyskinesias: an acute double-blind placebocontrolled study. Mov Disord. 2001;16(3):515-520.

31. Thomas A, Iacono D, Luciano AL, Armellino K, Di Iorio A, Onofrj M. Duration of amantadine benefit on dyskinesia of severe Parkinson's disease. J Neurol Neurosurg Psychiatry. 2004;75(1):141-143.

32. Wolf E, Seppi K, Katzenschlager R, et al. Long-term antidyskinetic efficacy of amantadine in Parkinson's disease. Mov Disord. 2010;25(10): $1357-1363$

33. Jahangirvand A, Rajput A. Early use of amantadine to prevent or delay onset of levodopainduced dyskinesia in Parkinson's disease. Mov Disord. 2013;28 Suppl 1:S207.
34. Pahwa R, Tanner CM, Hauser RA, et al. Randomized trial of extended release amantadine in Parkinson's disease patients with levodopainduced dyskinesia (EASED study). Mov Disord. 2013;28 Suppl 1: S158.

35. Parkinson Study Group. Evaluation of dyskinesias in a pilot, randomized, placebo-controlled trial of remacemide in advanced Parkinson disease. Arch Neurol. 2001;58(10):1660-1668.

36. Bara-Jimenez W, Dimitrova TD, Sherzai A, Aksu M, Chase TN. Glutamate release inhibition ineffective in levodopa-induced motor complications. Mov Disord. 2006;21(9):1380-1383.

37. Verhagen Metman L, Del Dotto P, Natte R, van den Munckhof P, Chase TN. Dextromethorphan improves levodopa-induced dyskinesias in Parkinson's disease. Neurology. 1998;51(1):203-206.

38. Zhang Y, Britto MR, Valderhaug KL, Wedlund PJ, Smith RA. Dextromethorphan: enhancing its systemic availability by way of low-dose quinidine-mediated inhibition of cytochrome P4502D6. Clin Pharmacol Ther. 1992;51(6):647-655.

39. Avanir Pharmaceuticals. Safety and Efficacy of AVP-923 in the Treatment of Levodopa-induced Dyskinesia in Parkinson's Disease Patients (LID in PD). In: ClinicalTrials.gov [website on the Internet]. Bethesda, MD: US National Library of Medicine; 2013 [updated July 29, 2013]. Available from: http://clinicaltrials.gov/show/NCT01767129. NLM identifier: NCT01767129. Accessed September 6, 2013.

40. Merello M, Nouzeilles MI, Cammarota A, Leiguarda R. Effect of memantine (NMDA antagonist) on Parkinson's disease: a doubleblind crossover randomized study. Clin Neuropharmacol. 1999;22(5): 273-276.

41. Moreau C, Delval A, Tiffreau V, et al. Memantine for axial signs in Parkinson's disease: a randomised, double-blind, placebo-controlled pilot study. J Neurol Neurosurg Psychiatry. 2013;84(5):552-555.

42. Varanese S, Howard J, Di Rocco A. NMDA antagonist memantine improves levodopa-induced dyskinesias and "on-off" phenomena in Parkinson's disease. Mov Disord. 2010;25(4):508-510.

43. Vidal EI, Fukushima FB, Valle AP, Villas Boas PJ. Unexpected improvement in levodopa-induced dyskinesia and on-off phenomena after introduction of memantine for treatment of Parkinson's disease dementia. J Am Geriatr Soc. 2013;61(1):170-172.

44. Wessell RH, Ahmed SM, Menniti FS, Dunbar GL, Chase TN, Oh JD. NR2B selective NMDA receptor antagonist CP-101,606 prevents levodopa-induced motor response alterations in hemi-parkinsonian rats. Neuropharmacology. 2004;47(2):184-194.

45. Nash JE, Ravenscroft P, McGuire S, Crossman AR, Menniti FS, Brotchie JM. The NR2B-selective NMDA receptor antagonist CP-101,606 exacerbates L-dopa-induced dyskinesia and provides mild potentiation of anti-parkinsonian effects of L-dopa in the MPTPlesioned marmoset model of Parkinson's disease. Exp Neurol. 2004; 188(2):471-479.

46. Nutt JG, Gunzler SA, Kirchhoff T, et al. Effects of a NR2B selective NMDA glutamate antagonist, CP-101,606, on dyskinesia and Parkinsonism. Mov Disord. 2008;23(13):1860-1866.

47. Neurim Pharmaceuticals Ltd. Safety, Tolerability, PK and PD Study of Neu-120 in the Treatment of Levodopa-induced Dyskinesia. In: ClinicalTrials.gov [website on the Internet]. Bethesda, MD: US National Library of Medicine; 2008 [updated June 9, 2011]. Available from: http://clinicaltrials.gov/ct2/show/NCT00607451?term=NCT00607451\& rank=1. NLM identifier: NCT00607451. Accessed September 6, 2013.

48. Picconi B, Pisani A, Centonze D, et al. Striatal metabotropic glutamate receptor function following experimental parkinsonism and chronic levodopa treatment. Brain. 2002;125(Pt 12):2635-2645.

49. Samadi P, Rajput A, Calon F, et al. Metabotropic glutamate receptor II in the brains of Parkinsonian patients. J Neuropathol Exp Neurol. 2009;68(4):374-382.

50. Masilamoni GJ, Bogenpohl JW, Alagille D, et al. Metabotropic glutamate receptor 5 antagonist protects dopaminergic and noradrenergic neurons from degeneration in MPTP-treated monkeys. Brain. 2011;134(Pt 7):2057-2073. 
51. Vernon AC, Palmer S, Datla KP, Zbarsky V, Croucher MJ, Dexter DT. Neuroprotective effects of metabotropic glutamate receptor ligands in a 6-hydroxydopamine rodent model of Parkinson's disease. Eur J Neurosci. 2005;22(7):1799-1806.

52. Mela F, Marti M, Dekundy A, Danysz W, Morari M, Cenci MA. Antagonism of metabotropic glutamate receptor type 5 attenuates 1-dopa-induced dyskinesia and its molecular and neurochemical correlates in a rat model of Parkinson's disease. J Neurochem. 2007;101(2): 483-497.

53. Rylander D, Recchia A, Mela F, Dekundy A, Danysz W, Cenci MA. Pharmacological modulation of glutamate transmission in a rat model of L-dopa-induced dyskinesia: effects on motor behavior and striatal nuclear signaling. J Pharmacol Exp Ther. 2009;330(1): $227-235$.

54. Johnston TH, Fox SH, McIldowie MJ, Piggott MJ, Brotchie JM. Reduction of L-dopa-induced dyskinesia by the selective metabotropic glutamate receptor 5 antagonist 3-[(2-methyl-1,3-thiazol-4-yl)ethynyl] pyridine in the 1-methyl-4-phenyl-1,2,3,6-tetrahydropyridine-lesioned macaque model of Parkinson's disease. J Pharmacol Exp Ther. 2010;333(3):865-873.

55. Levandis G, Bazzini E, Armentero MT, Nappi G, Blandini F. Systemic administration of an mGluR5 antagonist, but not unilateral subthalamic lesion, counteracts 1-dopa-induced dyskinesias in a rodent model of Parkinson's disease. Neurobiol Dis. 2008;29(1):161-168.

56. Dekundy A, Pietraszek M, Schaefer D, Cenci MA, Danysz W. Effects of group I metabotropic glutamate receptors blockade in experimental models of Parkinson's disease. Brain Res Bull. 2006;69(3): 318-326.

57. Grégoire L, Morin N, Ouattara B, et al. The acute antiparkinsonian and antidyskinetic effect of AFQ056, a novel metabotropic glutamate receptor type 5 antagonist, in L-dopa-treated parkinsonian monkeys. Parkinsonism Relat Disord. 2011;17(4):270-276.

58. Berg D, Godau J, Trenkwalder C, et al. AFQ056 treatment of levodopainduced dyskinesias: results of 2 randomized controlled trials. Mov Disord. 2011;26(7):1243-1250.

59. Stocchi F, Rascol O, Destee A, et al. AFQ056 in Parkinson patients with levodopa-induced dyskinesia: 13 -week, randomized, dose-finding study. Mov Disord. Epub July 12, 2013.

60. Novartis Pharmaceuticals. Open Label, Safety, Tolerability and Efficacy of AFQ056 in Parkinson's Patients With L-dopa Induced Dyskinesias. In: ClinicalTrials.gov [website on the Internet]. Bethesda, MD: US National Library of Medicine; 2010 [updated December 6, 2012]. Available from: http:/clinicaltrials.gov/ct2/show/NCT01173731?term= NCT01173731\&rank=1. NLM identifier: NCT01173731. Accessed September 6, 2013.

61. Tison F, Durif F, Christophe J, et al. Safety, tolerability and antidyskinetic efficacy of dipraglurant, a novel mGluR5 negative allosteric modulator (NAM) in Parkinson's disease (PD) patients with levodopainduced dyskinesia. Poster presented at: 65th American Academy of Neurology Annual Meeting; March 16-23, 2013; San Diego, CA, USA.

62. Konitsiotis S, Blanchet PJ, Verhagen L, Lamers E, Chase TN. AMPA receptor blockade improves levodopa-induced dyskinesia in MPTP monkeys. Neurology. 2000;54(8):1589-1595.

63. National Institute of Neurological Disorders and Stroke (NINDS). Talampanel to Treat Parkinson's Disease. In: ClinicalTrials.gov [website on the Internet]. Bethesda, MD: US National Library of Medicine; 2005 [updated March 3, 2008]. Available from: http://clinicaltrials.gov/ct2/ show/NCT00108667?term=NCT00108667\&rank=1. NLM identifier: NCT00108667. Accessed September 6, 2013.

64. Teva Pharmaceutical Industries. Effects of Talampanel on Patients With Advanced Parkinson's Disease. In: ClinicalTrials.gov [website on the Internet]. Bethesda, MD: US National Library of Medicine; 2002 [updated April 11, 2011]. Available from: http://clinicaltrials. gov/ct2/show/NCT00036296?term=NCT00036296\&rank=1. Accessed September 6, 2013.
65. National Institute of Neurological Disorders and Stroke (NINDS). Study of LY300164 for the Treatment of Parkinson's Disease. In: ClinicalTrials.gov [website on the Internet]. Bethesda, MD: US National Library of Medicine; 2000 [updated March 3, 2008]. Available from: http://clinicaltrials.gov/ct2/show/NCT00004576?term=NCT00004576 \&rank=1. Accessed September 6, 2013.

66. Eggert K, Squillacote D, Barone P, et al. Safety and efficacy of perampanel in advanced Parkinson's disease: a randomized, placebocontrolled study. Mov Disord. 2010;25(7):896-905.

67. Lees A, Fahn S, Eggert KM, et al. Perampanel, an AMPA antagonist, found to have no benefit in reducing "off" time in Parkinson's disease. Mov Disord. 2012;27(2):284-288.

68. Rascol O, Barone P, Behari M, et al. Perampanel in Parkinson disease fluctuations: a double-blind randomized trial with placebo and entacapone. Clin Neuropharmacol. 2012;35(1):15-20.

69. Savola JM, Hill M, Engstrom M, et al. Fipamezole (JP-1730) is a potent alpha2 adrenergic receptor antagonist that reduces levodopa-induced dyskinesia in the MPTP-lesioned primate model of Parkinson's disease. Mov Disord. 2003;18(8):872-883.

70. Henry B, Fox SH, Peggs D, Crossman AR, Brotchie JM. The alpha2adrenergic receptor antagonist idazoxan reduces dyskinesia and enhances anti-parkinsonian actions of L-dopa in the MPTP-lesioned primate model of Parkinson's disease. Mov Disord. 1999;14(5): 744-753.

71. Grondin R, Hadj Tahar A, Doan VD, Ladure P, Bedard PJ. Noradrenoceptor antagonism with idazoxan improves L-dopainduced dyskinesias in MPTP monkeys. Naunyn Schmiedebergs Arch Pharmacol. 2000;361(2):181-186.

72. Rascol O, Arnulf I, Peyro-Saint Paul H, et al. Idazoxan, an alpha-2 antagonist, and L-dopa-induced dyskinesias in patients with Parkinson's disease. Mov Disord. 2001;16(4):708-713.

73. Manson AJ, Iakovidou E, Lees AJ. Idazoxan is ineffective for levodopainduced dyskinesias in Parkinson's disease. Mov Disord. 2000;15(2): 336-337.

74. Lewitt PA, Hauser RA, Lu M, et al. Randomized clinical trial of fipamezole for dyskinesia in Parkinson disease (FJORD study). Neurology. 2012;79(2):163-169.

75. Valeant Pharmaceuticals International, Inc. A Study of Safety and Tolerability of Fipamezole in Adult Subjects With Parkinson's Disease Who Are Receiving Levodopa. In: ClinicalTrials.gov [website on the Internet]. Bethesda, MD: US National Library of Medicine; 2010 [updated August 30, 2011]. Available from: http://clinicaltrials.gov/ct2/ show/NCT01140841?term=NCT01140841\&rank=1. NLM identifier: NCT01140841. Accessed September 6, 2013.

76. Valeant Pharmaceuticals International, Inc. A Study Comparing the Safety and Tolerability of Two Doses of Fipamezole in Adult Patients With Parkinson's Disease. In: ClinicalTrials.gov [website on the Internet]. Bethesda, MD: US National Library of Medicine; 2010 [updated June 20, 2012]. Available from: http://clinicaltrials.gov/ct2/ show/NCT01149811?term=NCT01149811\&rank=1. NLM identifier: NCT01149811. Accessed September 6, 2013.

77. Hickey P, Stacy M. Adenosine A2A antagonists in Parkinson's disease: what's next? Curr Neurol Neurosci Rep. 2012;12(4): 376-385.

78. Mori A, Shindou T. Modulation of GABAergic transmission in the striatopallidal system by adenosine $\mathrm{A} 2 \mathrm{~A}$ receptors: a potential mechanism for the antiparkinsonian effects of A2A antagonists. Neurology. 2003; 61(11 Suppl 6):S44-S48.

79. Morelli M, Di Paolo T, Wardas J, Calon F, Xiao D, Schwarzschild MA. Role of adenosine A2A receptors in parkinsonian motor impairment and 1-dopa-induced motor complications. Prog Neurobiol. 2007;83(5): 293-309.

80. Calon F, Dridi M, Hornykiewicz O, Bedard PJ, Rajput AH, Di Paolo T. Increased adenosine A2A receptors in the brain of Parkinson's disease patients with dyskinesias. Brain. 2004;127(Pt 5): 1075-1084. 
81. Carta AR, Pinna A, Cauli O, Morelli M. Differential regulation of GAD67, enkephalin and dynorphin mRNAs by chronic-intermittent L-dopa and A2A receptor blockade plus L-dopa in dopamine-denervated rats. Synapse. 2002;44(3):166-174.

82. Hodgson RA, Bertorelli R, Varty GB, et al. Characterization of the potent and highly selective A2A receptor antagonists preladenant and SCH 412348 [7-[2-[4-2,4-difluorophenyl]-1-piperazinyl]ethyl]-2-(2furanyl)-7H-pyrazolo[4,3-e][1,2,4]triazolo[1,5-c]pyrimidin-5-amine $]$ in rodent models of movement disorders and depression. J Pharmacol Exp Ther. 2009;330(1):294-303.

83. Hodgson RA, Bedard PJ, Varty GB, et al. Preladenant, a selective $\mathrm{A}(2 \mathrm{~A})$ receptor antagonist, is active in primate models of movement disorders. Exp Neurol. 2010;225(2):384-390.

84. Hauser RA, Cantillon M, Pourcher E, et al. Preladenant in patients with Parkinson's disease and motor fluctuations: a phase 2, double-blind, randomised trial. Lancet Neurol. 2011;10(3):221-229.

85. Factor SA, Wolski K, Togasaki DM, et al. Long-term safety and efficacy of preladenant in subjects with fluctuating Parkinson's disease. Mov Disord. 2013;28(6):817-820.

86. Hauser RA, Shulman LM, Trugman JM, et al. Study of istradefylline in patients with Parkinson's disease on levodopa with motor fluctuations. Mov Disord. 2008;23(15):2177-2185.

87. LeWitt PA, Guttman M, Tetrud JW, et al. Adenosine A2A receptor antagonist istradefylline (KW-6002) reduces "off" time in Parkinson's disease: a double-blind, randomized, multicenter clinical trial (6002US-005). Ann Neurol. 2008;63(3):295-302.

88. Pourcher E, Fernandez HH, Stacy M, Mori A, Ballerini R, Chaikin P. Istradefylline for Parkinson's disease patients experiencing motor fluctuations: results of the KW-6002-US-018 study. Parkinsonism Relat Disord. 2012;18(2):178-184.

89. Mizuno Y, Hasegawa K, Kondo T, Kuno S, Yamamoto M. Clinical efficacy of istradefylline (KW-6002) in Parkinson's disease: a randomized, controlled study. Mov Disord. 2010;25(10):1437-1443.

90. Bara-Jimenez W, Sherzai A, Dimitrova T, et al. Adenosine A(2A) receptor antagonist treatment of Parkinson's disease. Neurology. 2003;61(3):293-296.

91. Hauser RA, Olanow CW, Kieburtz K, et al. A phase 2, placebocontrolled, randomized, double-blind trial of tozadenant (SYN-115) in patients with Parkinson's disease with wearing-off fluctuations on levodopa. Mov Disord. 2013;28 Suppl 1:S158.

92. Wonnacott S. Presynaptic nicotinic ACh receptors. Trends Neurosci. 1997;20(2):92-98.

93. Zhou FM, Liang Y, Dani JA. Endogenous nicotinic cholinergic activity regulates dopamine release in the striatum. Nat Neurosci. 2001;4(12):1224-1229.

94. Bordia T, Campos C, Huang L, Quik M. Continuous and intermittent nicotine treatment reduces L-3,4-dihydroxyphenylalanine (L-dopa)induced dyskinesias in a rat model of Parkinson's disease. J Pharmacol Exp Ther. 2008;327(1):239-247.

95. Quik M, Cox H, Parameswaran N, O'Leary K, Langston JW, Di Monte D. Nicotine reduces levodopa-induced dyskinesias in lesioned monkeys. Ann Neurol. 2007;62(6):588-596.

96. Quik M, Mallela A, Chin M, McIntosh JM, Perez XA, Bordia T. Nicotine-mediated improvement in L-dopa-induced dyskinesias in MPTP-lesioned monkeys is dependent on dopamine nerve terminal function. Neurobiol Dis. 2013;50:30-41.

97. Quik M, Mallela A, Ly J, Zhang D. Nicotine reduces established levodopa-induced dyskinesias in a monkey model of Parkinson's disease. Mov Disord. Epub July 8, 2013.

98. Lemay S, Chouinard S, Blanchet P, et al. Lack of efficacy of a nicotine transdermal treatment on motor and cognitive deficits in Parkinson's disease. Prog Neuropsychopharmacol Biol Psychiatry. 2004;28(1): 31-39.

99. Parkinson Study Group. Randomized placebo-controlled study of the nicotinic agonist SIB-1508Y in Parkinson disease. Neurology. 2006;66(3):408-410.
100. Villafane G, Cesaro P, Rialland A, et al. Chronic high dose transdermal nicotine in Parkinson's disease: an open trial. Eur J Neurol. 2007; 14(12):1313-1316.

101. Vieregge A, Sieberer M, Jacobs H, Hagenah JM, Vieregge P. Transdermal nicotine in PD: a randomized, double-blind, placebocontrolled study. Neurology. 2001;57(6):1032-1035.

102. Neuraltus Pharmaceuticals, Inc. Study of NP002 in Subjects With Idiopathic Parkinson's Disease to Treat Dyskinesias Due to Levodopa Therapy. In: ClinicalTrials.gov [website on the Internet]. Bethesda, MD: US National Library of Medicine; 2009 [updated September 26, 2011]. Available from: http://clinicaltrials.gov/ct2/show/NCT009579 18?term=NCT00957918\&rank=1. NLM identifier: NCT00957918. Accessed September 6, 2013.

103. Bordia T, Campos C, McIntosh JM, Quik M. Nicotinic receptormediated reduction in L-dopa-induced dyskinesias may occur via desensitization. J Pharmacol Exp Ther. 2010;333(3):929-938.

104. Huang LZ, Campos C, Ly J, Ivy Carroll F, Quik M. Nicotinic receptor agonists decrease L-dopa-induced dyskinesias most effectively in partially lesioned parkinsonian rats. Neuropharmacology. 2011;60(6): 861-868.

105. Meco G, Stirpe P, Edito F, et al. Aripiprazole in L-dopa-induced dyskinesias: a one-year open-label pilot study. J Neural Transm. 2009;116(7):881-884

106. Tayarani-Binazir K, Jackson MJ, Rose S, McCreary AC, Jenner P. The partial dopamine agonist pardoprunox (SLV308) administered in combination with 1-dopa improves efficacy and decreases dyskinesia in MPTP treated common marmosets. Exp Neurol. 2010;226(2): 320-327.

107. Bronzova J, Sampaio C, Hauser RA, et al. Double-blind study of pardoprunox, a new partial dopamine agonist, in early Parkinson's disease. Mov Disord. 2010;25(6):738-746.

108. Rascol O, Bronzova J, Hauser RA, et al. Pardoprunox as adjunct therapy to levodopa in patients with Parkinson's disease experiencing motor fluctuations: results of a double-blind, randomized, placebocontrolled, trial. Parkinsonism Relat Disord. 2012;18(4):370-376.

109. Hauser RA, Bronzova J, Sampaio C, et al. Safety and tolerability of pardoprunox, a new partial dopamine agonist, in a randomized, controlled study of patients with advanced Parkinson's disease. Eur Neurol. 2009;62(1):40-48.

110. Ligand Pharmaceuticals. The Effects of Aplindore on the Treatment of Signs and Symptoms of Parkinson's Disease. In: ClinicalTrials. gov [website on the Internet]. Bethesda, MD: US National Library of Medicine; 2008 [updated September 29, 2011]. Available from: http:// clinicaltrials.gov/ct2/show/NCT00623324?term $=$ NCT00623324\&ran k=1. NLM identifier: NCT00623324. Accessed September 6, 2013.

111. Waters CH, Sethi KD, Hauser RA, Molho E, Bertoni JM. Zydis selegiline reduces off time in Parkinson's disease patients with motor fluctuations: a 3-month, randomized, placebo-controlled study. Mov Disord. 2004;19(4):426-432.

112. Rascol O, Brooks DJ, Melamed E, et al. Rasagiline as an adjunct to levodopa in patients with Parkinson's disease and motor fluctuations (LARGO, Lasting Effect in Adjunct Therapy with Rasagiline Given Once Daily, study): a randomised, double-blind, parallel-group trial. Lancet. 2005;365(9463):947-954.

113. Grégoire L, Jourdain VA, Townsend M, Roach A, Di Paolo T. Safinamide reduces dyskinesias and prolongs 1-DOPA antiparkinsonian effect in parkinsonian monkeys. Parkinsonism Relat Disord. 2013;19(5):508-514.

114. Borgohain R, Szasz J, Stanzione P. First 2-year, controlled study to assess safinamide as add-on to levodopa in Parkinson's disease with motor fluctuations. Mov Disord. 2011;26 Suppl 2:S120.

115. Shoulson I, Oakes D, Fahn S, et al. Impact of sustained deprenyl (selegiline) in levodopa-treated Parkinson's disease: a randomized placebo-controlled extension of the deprenyl and tocopherol antioxidative therapy of parkinsonism trial. Ann Neurol. 2002;51(5): 604-612. 
116. Talati R, Reinhart K, Baker W, White CM, Coleman CI. Pharmacologic treatment of advanced Parkinson's disease: a meta-analysis of COMT inhibitors and MAO-B inhibitors. Parkinsonism Relat Disord. 2009;15(7):500-505.

117. Tomiyama M, Kimura T, Maeda T, Kannari K, Matsunaga M, Baba M. A serotonin 5-HT1A receptor agonist prevents behavioral sensitization to L-dopa in a rodent model of Parkinson's disease. Neurosci Res. 2005;52(2):185-194.

118. Kannari K, Kurahashi K, Tomiyama M, et al. Tandospirone citrate, a selective 5-HT1A agonist, alleviates L-DOPA-induced dyskinesia in patients with Parkinson's disease. No To Shinkei. 2002;54(2): 133-137.

119. Olanow CW, Damier P, Goetz CG, et al. Multicenter, open-label, trial of sarizotan in Parkinson disease patients with levodopa-induced dyskinesias (the SPLENDID Study). Clin Neuropharmacol. 2004;27(2):58-62.

120. Goetz CG, Laska E, Hicking C, et al. Placebo influences on dyskinesia in Parkinson's disease. Mov Disord. 2008;23(5):700-707.

121. Rascol O, Damier P, Goetz CG, et al. A large phase III study to evaluate the safety and efficacy of sarizotan in the treatment of L-dopa-induced dyskinesia associated with Parkinson's disease: the Paddy-1 study. Mov Disord. 2006;21 Suppl 15:S492-S493.

122. Müller T, Olanow CW, Nutt J, et al. The PADDY-2 study: the evaluation of sarizotan for treatment-associated dyskinesia in Parkinson's disease patients. Mov Disord. 2006;21 Suppl 15:S591.

123. Asubio Pharmaceuticals, Inc. Preliminary Study of Piclozotan in Patients With Motor Complications Associated With Parkinson's Disease. In: ClinicalTrials.gov [website on the Internet]. Bethesda, MD: US National Library of Medicine; 2008 [updated April 4, 2011] Available from: http://clinicaltrials.gov/ct2/show/NCT00623363? term=NCT00623363\&rank=1. NLM identifier: NCT00623363. Accessed September 6, 2013.

124. Bezard E, Tronci E, Pioli EY, et al. Study of the antidyskinetic effect of eltoprazine in animal models of levodopa-induced dyskinesia. Mov Disord. 2013;28(8):1088-1096.

125. NeuroSearch initiates a clinical study with ACR325 for the treatment of dyskinesias (involuntary movements) in Parkinson's disease [webpage on the Internet]. Copenhagen: NeuroSearch A/S; 2009. Available from https://newsclient.omxgroup.com/cdsPublic/viewDisclosure.action? disclosureId=368187\&messageId=439581. Accessed September 26, 2013.
126. Price PA, Parkes JD, Marsden CD. Sodium valproate in the treatment of levodopa-induced dyskinesia. J Neurol Neurosurg Psychiatry. 1978;41(8):702-706.

127. Van Blercom N, Lasa A, Verger K, Masramon X, Sastre VM, Linazasoro G. Effects of gabapentin on the motor response to levodopa: a doubleblind, placebo-controlled, crossover study in patients with complicated Parkinson disease. Clin Neuropharmacol. 2004;27(3):124-128.

128. Murata M, Hasegawa K, Kanazawa I. Zonisamide improves motor function in Parkinson disease: a randomized, double-blind study. Neurology. 2007;68(1):45-50.

129. Wong KK, Alty JE, Goy AG, Raghav S, Reutens DC, Kempster PA. A randomized, double-blind, placebo-controlled trial of levetiracetam for dyskinesia in Parkinson's disease. Mov Disord. 2011;26(8): 1552-1555.

130. Stathis P, Konitsiotis S, Tagaris G, Peterson D. Levetiracetam for the management of levodopa-induced dyskinesias in Parkinson's disease. Mov Disord. 2011;26(2):264-270.

131. Wolz M, Lohle M, Strecker K, et al. Levetiracetam for levodopa-induced dyskinesia in Parkinson's disease: a randomized, double-blind, placebocontrolled trial. J Neural Transm. 2010;117(11):1279-1286.

132. University Health Network, Toronto. Topiramate as a Treatment for Levodopa-Induced Dyskinesia in Parkinson's Disease. In: ClinicalTrials.gov [website on the Internet]. Bethesda, MD: US National Library of Medicine; 2006 [updated September 19, 2007] Available from: http://clinicaltrials.gov/ct2/show/NCT00296959? term $=$ NCT00296959\&rank=1. NLM identifier: NCT00296959. Accessed September 6, 2013

133. NeuroSearch A/S. Safety and Tolerability Study Evaluating ACR 325 in Parkinson's Disease Patients. In: ClinicalTrials.gov [website on the Internet]. Bethesda, MD: US National Library of Medicine; 2009 [updated November 1, 2011]. Available from: http://clinicaltrials. gov/ct2/show/NCT01023282?term=NCT01023282\&rank=1. NLM identifier: NCT01023282. Accessed September 6, 2013.

134. Huot P, Brotchie JM. 5-HT(1A) receptor stimulation and L-dopainduced dyskinesia in Parkinson's disease: bridging the gap between serotonergic and glutamatergic mechanisms. Exp Neurol. 2011;231(2): 195-198.

135. Huot P, Johnston TH, Koprich JB, Fox SH, Brotchie JM. The pharmacology of L-dopa-induced dyskinesia in Parkinson's disease. Pharmacol Rev. 2013;65(1):171-222.
Neuropsychiatric Disease and Treatment

\section{Publish your work in this journal}

Neuropsychiatric Disease and Treatment is an international, peerreviewed journal of clinical therapeutics and pharmacology focusing on concise rapid reporting of clinical or pre-clinical studies on a range of neuropsychiatric and neurological disorders. This journal is indexed on PubMed Central, the 'PsycINFO' database and CAS

\section{Dovepress}

The manuscript management system is completely online and includes a very quick and fair peer-review system, which is all easy to use. Visit http://www.dovepress.com/testimonials.php to read real quotes from published authors. 